\title{
Pretreatment by omalizumab allows allergen- specific immunotherapy in children and young adult with severe allergic asthma
}

\author{
Nathalie Lambert ${ }^{*}$, Tamazoust Guiddir, Jocelyne Just, Flore Amat \\ From 2nd International Severe Asthma Forum (ISAF) \\ Athens, Greece. 13-15 November 2014
}

\section{Background}

Subcutaneous allergen-specific immunotherapy (SCIT) is a valuable treatment option for patients with controlled mild to moderate allergic asthma However, SCIT is contraindicated for patients with severe persistent asthma due to a potential systemic allergic reaction. Several studies in adolescents and adults with persistent allergic rhinitis and moderate persistent allergic asthma have shown that SCIT is better tolerated when combined with. Nevertheless, no previous studies have been conducted in children and adolescents with severe asthma to assess the safety and efficacy of a combination treatment of SCIT and omalizumab.

\section{Methods}

We report here the observations of six patients, aged 11 to 21 years, with severe persistent asthma controlled by omalizumab as add-on therapy who received SCIT under a cluster protocol during omalizumab treatment and then SCIT maintenance alone after discontinuation of omalizumab.

\section{Results}

Although no patients experienced severe exacerbation, one patient had to stop SCIT after one month of treatment because of uncontrolled asthma. For the five remaining patients, asthma control continued to improve during the combined treatment with SCIT and omalizumab (median time duration $=8$ months) despite a decrease in maintenance treatment for all of them. SCIT was continued alone for a median time of 25.5 months and was well tolerated. For these patients, asthma was totally controlled

Armand Trousseau Children's Hospital, Allergology Department, Paris, France and therapeutic levels of maintenance treatment could be further reduced

\section{Conclusion}

Pretreatment by omalizumab for patients with persistent severe allergic asthma seems to improve the safety and probably also the efficacy of SCIT. These results open up perspectives of SCIT for children suffering from severe allergic asthma. However,the primary outcomes of these observations are not included in a standardized protocol and will require further confirmation by prospective double blind studies.

Published: 23 March 2015

doi:10.1186/2045-7022-5-S2-P1

Cite this article as: Lambert et al: Pretreatment by omalizumab allows allergen-specific immunotherapy in children and young adult with severe allergic asthma. Clinical and Translational Allergy 2015 5(Suppl 2):P1.

Submit your next manuscript to BioMed Central and take full advantage of:

- Convenient online submission

- Thorough peer review

- No space constraints or color figure charges

- Immediate publication on acceptance

- Inclusion in PubMed, CAS, Scopus and Google Scholar

- Research which is freely available for redistribution 